ORIGINAL ARTICLE

\title{
When one is not enough: prevalence and characteristics of homes not adequately protected by smoke alarms
}

\author{
C Peek-Asa, V Allareddy, J Yang, C Taylor, J Lundell, C Zwerling
}

Injury Prevention 2005;11:364-368. doi: 10.1136/ip.2005.009175

See end of article for authors' affiliations

\section{Correspondence to:}

Professor C Peek-Asa, 100

Oakdale Blvd. \#114 IREH,

lowa City, IA 52242, USA;

corinne-peek-asa@uiowa.

edu

Accepted 28 August 2005
Objective: The National Fire Protection Association (NFPA) has specific recommendations about the number, location, and type of smoke alarms that are needed to provide maximum protection for a household. No previous studies have examined whether or not homes are completely protected according to these guidelines. The authors describe the prevalence and home characteristics associated with compliance to recommendations for smoke alarm installation by the NFPA.

Design, setting, and subjects: Data are from the baseline on-site survey of a randomized trial to measure smoke alarm effectiveness. The trial was housed in a longitudinal cohort study in a rural lowa county. Of 1005 homes invited, 691 (68.8\%) participated.

Main outcome measures: Information about smoke alarm type, placement, and function, as well as home and occupant characteristics, was collected through an on-site household survey.

Results: Although $86.0 \%$ of homes had at least one smoke alarm, only $22.3 \%$ of homes (approximately one in five) were adequately protected according to NFPA guidelines. Fourteen percent of homes had no functioning smoke alarms. More than half of the homes with smoke alarms did not have enough of them or had installed them incorrectly, and $42.4 \%$ of homes with alarms had at least one alarm that did not operate. Homes with at least one high school graduate were nearly four times more likely to be fully protected. Homes that had multiple levels, a basement, or were cluttered or poorly cleaned were significantly less likely to be fully protected.

Conclusion: These findings indicate that consumers may not be knowledgeable about the number of alarms they need or how to properly install them. Occupants are also not adequately maintaining the alarms that are installed.
A ccording to the National Fire Protection Association (NFPA), US fire departments respond to a fire every 19 seconds. ${ }^{1}$ In 2002, an estimated 401000 home fires occurred in the US, killing 2695 civilians (one per 100 000), injuring an estimated 14050 , and causing more than $\$ 6$ billion in damage. ${ }^{1}$ Fire deaths and injuries have decreased in the last 20 years, yet home fires still cause $79 \%$ of all fire deaths and $68 \%$ of fire injuries. ${ }^{12}$ The fire death rate is $36 \%$ higher in rural than urban areas. ${ }^{2}$

Most home fire deaths occur from smoke inhalationoften before flames engulf the home. ${ }^{3}$ Smoke alarms, when properly installed and maintained, are one of the most effective ways to prevent deaths and injuries from fires. ${ }^{4}$ Home smoke alarms reduce the risk of dying in a fire by half. ${ }^{6}$ However, nearly one third of home fires in the US occur in homes without functioning smoke alarms. ${ }^{6-9}$ The proportion of all US homes with smoke alarms is lower in rural areas (85.8\%) than in urban areas (92.9\%). ${ }^{10}{ }^{11}$ Existing research on smoke alarm ownership focuses on whether or not homes have at least one smoke alarm. While most studies measure the presence of at least one functional smoke alarm, ${ }^{910^{12-15}}$ others measure the presence of an alarm without regard to function. ${ }^{16-19}$ Most of these studies are based on self report of smoke alarm ownership and function, usually over the telephone, ${ }^{10}{ }^{13}{ }^{16-19}$ and only a few are based on home inspections. ${ }^{4}{ }^{14} 15$

These studies have found a wide range of smoke alarm ownership, from a low of $16 \%$ in a 1996 home inspection program in a low income inner city London neighborhood ${ }^{15}$ to a high of $97 \%$ reported through a weighted national phone survey. ${ }^{19}$ One study found that only $54.4 \%$ of London homes had functional smoke alarms upon home inspection even after smoke alarms had been installed through a research study 15 months earlier. ${ }^{14}$

Only three studies have examined smoke alarm location, all of which asked through phone interview about the presence of smoke alarms on each floor. Although smoke alarm ownership was over $90 \%$ in all three studies, $14-20 \%$ of homes lacked an alarm on each level. ${ }^{10} 1619$

Homes may not be adequately protected even if at least one working smoke alarm is present. The National Fire Protection Association requires, at a minimum, at least one alarm on every level of the structure, one by each sleeping area, and has further requirements about the exact location, types, and mounting for each alarm. ${ }^{20}$ To date, no study has examined the proportion of homes that meets these NFPA requirements to be fully protected by smoke alarms. In this study, we use data from home inspections in a rural Iowa county to identify the prevalence and characteristics of homes that are protected by smoke alarms according to NFPA guidelines.

\section{METHODS}

\section{Study population and design}

Household smoke alarm inspections were conducted as part of the baseline survey of a randomized trial to study smoke alarm effectiveness. The trial was nested within a longitudinal cohort study that has been described previously. ${ }^{21}$ For the smoke alarm trial, letters of invitation were sent to the 1187 households that had participated in either the first or second round of the cohort study. Of these, three $(0.3 \%)$ cohort participants had died, two had moved out of the county $(0.2 \%)$, and $177(14.9 \%)$ could no longer be located.

Abbreviation: NFPA, National Fire Protection Association. 
Of the 1005 households that were located, 691 (68.8\%) agreed to participate. Both the cohort study and smoke alarm trial were approved by the University of Iowa Human Subject Protection Committee.

\section{Data collection}

Households participating in the smoke alarm trial were visited by a trained researcher. Participants responded to a baseline survey which contained questions on demographic and household characteristics, smoking in the home, previous fires, and fire safety practices. Before installing study alarms, researchers examined the placement and function of existing smoke alarms. Alarm function was tested using artificial smoke. Researchers were trained on the National Fire Protection Association guidelines for smoke alarm installation, ${ }^{20}$ and assessed at baseline if each home was protected by smoke alarms according to these guidelines. Homes that met guidelines were considered to be fully protected, and those not meeting guidelines were not.

Homes were considered to be damaged or poorly maintained if they had any of the following: holes in the structure, including windows; visible water damage; peeling paint; excessively overgrown yard (excluding long grass); or general dilapidation. Homes were considered to be poorly cleaned or cluttered if they had any of the following: visible dirt and/or stains on walls or furniture; food left out that was visibly rotten; piled-up unclean dishes; or clutter that prevents access to furniture or movement through the room. Supplemental heating sources included the use of wood or coal burning fireplaces or stoves.

Information about education, income, alcohol use, and depression were obtained from the original cohort data. The time lag between data collection for the original cohort and the baseline survey was less than 24 months for the majority of households, and household composition remained largely stable. Data for the cohort study were collected during a private interview by a trained nurse in a study clinic that is located in the county's largest town. Alcohol use was measured using the CAGE questionnaire, and positive responses to two or more items were considered a potential alcohol problem. ${ }^{22-24}$ Depressive symptoms were measured using the 11 item short version of the CES-D Depression Scale. Individuals with a score of eight or more were considered to have depressive symptoms. ${ }^{25}{ }^{26}$ For this study, households were considered positive for potential alcohol problems or depressive symptoms if any adult in the household was positive.

\section{Analysis}

Risk ratios were calculated to predict the binary outcome of whether or not the home was fully protected according to NFPA guidelines. Independent variables were chosen based on their association with smoke alarm ownership in previous literature. Risk ratios were calculated with the log binomial model using PROC GENMOD run on SAS version 8.2 (SAS Institute Inc, Cary, NC, USA). The log binomial model was used to directly estimate risk ratios with an outcome that is not rare. ${ }^{27}$

After examining independent variables based on previous literature, we developed a multivariate model that best predicted full protection by NFPA guidelines. All variables that were significant with an alpha level of 0.10 were tested for inclusion in the multivariate model. The final model included the combination of variables that led to the best Hosmer and Lemeshow goodness-of-fit statistic. ${ }^{28}$ For the log binomial model, goodness-of-fit statistics partition the predicted values into deciles and then compare expected with observed values for the group indicator. Thus, an individual with a high predicted probability of group membership would be placed in the upper deciles. If the independent variables are good predictors of the outcome, the deviance will be close to one and the $\mathrm{p}$ value will be large and insignificant. Variables for the final models were chosen based on the optimal deviance and p value. A Monte Carlo simulation using a random $66 \%$ sample selection was used to test the validity of the predictive model.

\section{RESULTS}

Of the 691 participating homes, only 154 (22.3\%) were adequately protected by smoke alarms according to NFPA guidelines (table 1). In order to be completely protected, the home needed to have alarms installed according to NFPA guidelines and each alarm had to respond to a test with artificial smoke. The majority $(86.0 \%)$ of homes did have at least one smoke alarm installed, and 495 (71.6\%) had at least one functional alarm. Among the 594 homes with smoke alarms, 339 (57\%) did not have them installed correctly. The main reason for incorrect installation was the absence of an alarm on every household level (85\%), and not having an alarm in the basement was the most common. Other deficiencies in smoke alarm installation (not mutually exclusive) included alarms placed in incorrect locations ( $11 \%)$, being incorrectly mounted $(8 \%)$, and not having the appropriate alarm features (2\%) Although the NFPA guidelines specify a number of required features, the $2 \%$ in this sample all failed the single requirement that alarms within four feet of the kitchen must have a silencing feature. $42.4 \%$ of homes with a smoke alarm had at least one alarm that was not functioning.

Table 2 lists occupant and home factors that have been associated with smoke alarm ownership or function in previous literature and shows their relation with the likelihood of a home being fully protected. Among occupant characteristics, the presence of at least one resident with an educational status of high school or higher was associated with a 3.7 times increase in likelihood of being fully protected. Occupants who reported testing or changing their smoke alarm batteries within the past six months were more than two times more likely to be fully protected. The presence of at least one household member who had depressive symptoms based on the CES-D Depression Scale were slightly less likely to be fully protected, and those that were married

Table 1 Smoke alarm installation and function among 691 homes in a rural county

\begin{tabular}{|c|c|c|}
\hline Smoke alarm status & $\mathbf{n}$ & (\%) \\
\hline \multicolumn{3}{|c|}{ Alarms were present in the home $(n=691)$} \\
\hline Yes & 594 & 86.0 \\
\hline No & 97 & 14.0 \\
\hline \multicolumn{3}{|c|}{$\begin{array}{l}\text { Home had at least one functional smoke alarm } \\
(n=691)\end{array}$} \\
\hline Yes & 495 & 71.6 \\
\hline No & 196 & 28.4 \\
\hline \multicolumn{3}{|c|}{$\begin{array}{l}\text { Alarms were installed to meet NFPA guidelines } \\
\text { ( } n=594 \text { homes with alarms) }\end{array}$} \\
\hline Yes & 255 & 43.0 \\
\hline No & 339 & 57.1 \\
\hline \multicolumn{3}{|c|}{$\begin{array}{l}\text { All alarms were functioning* ( } \mathrm{n}=594 \text { homes with } \\
\text { alarms) }\end{array}$} \\
\hline Yes & 342 & 57.6 \\
\hline No & 252 & 42.4 \\
\hline \multicolumn{3}{|c|}{$\begin{array}{l}\text { Home was protected according to NFPA } \\
\text { guidelinest }(n=691)\end{array}$} \\
\hline Yes & 154 & 22.3 \\
\hline No & 537 & 77.7 \\
\hline
\end{tabular}




\begin{tabular}{|c|c|c|c|c|}
\hline \multirow[b]{3}{*}{ Characteristics } & \multicolumn{4}{|c|}{ NFPA protection status } \\
\hline & \multirow[b]{2}{*}{ Total (\%) } & \multirow{2}{*}{$\frac{\text { Yes }}{\mathrm{n}(\%)}$} & \multirow{2}{*}{$\frac{\text { No }}{n(\%)}$} & \multirow[b]{2}{*}{ Risk ratio $(95 \% \mathrm{Cl})$} \\
\hline & & & & \\
\hline \multicolumn{5}{|c|}{ Occupant characteristics } \\
\hline \multicolumn{5}{|c|}{ At least one resident had alcohol problems } \\
\hline No & $569(82.5)$ & $\begin{array}{r}28(23.1) \\
126(22.1)\end{array}$ & $443(77.9)$ & $\begin{array}{l}1.04(0.73-1.50) \\
1.00\end{array}$ \\
\hline \multicolumn{5}{|c|}{ At least one current smoker } \\
\hline Yes & $110(15.9)$ & $19(17.3)$ & $91(82.7)$ & $0.74(0.48-1.14)$ \\
\hline No & $580(84.1)$ & $135(23.3)$ & $445(76.7)$ & 1.00 \\
\hline \multicolumn{5}{|c|}{ At least one resident with depressive symptoms } \\
\hline Yes & $191(27.7)$ & $33(17.3)$ & $158(29.5)$ & $0.71(0.50-1.01)$ \\
\hline No & $499(72.3)$ & $121(24.2)$ & $378(75.8)$ & 1.00 \\
\hline \multicolumn{5}{|c|}{ At least one resident is married } \\
\hline Yes & $493(71.4)$ & $119(24.1)$ & $374(75.9)$ & $1.35(0.96-1.90)$ \\
\hline No & $197(28.6)$ & $35(17.8)$ & $162(82.2)$ & 1.00 \\
\hline \multicolumn{5}{|c|}{ Household income $\geqslant \$ 20,000$} \\
\hline Yes & $599(87.4)$ & $137(22.9)$ & $462(77.1)$ & $1.31(0.81-2.12)$ \\
\hline No & $86(12.6)$ & 15 (17.4) & $71(82.6)$ & 1.00 \\
\hline \multicolumn{5}{|c|}{ At least one resident had high school or higher education } \\
\hline Yes & $658(95.4)$ & $152(23.1)$ & $506(76.9)$ & $3.69(0.96-14.24)$ \\
\hline No & $32(4.6)$ & $2(6.3)$ & 30 (93.8) & 1.00 \\
\hline \multicolumn{5}{|c|}{ Resident lived alone } \\
\hline Yes & $170(24.6)$ & $32(18.8)$ & $138(81.2)$ & $0.80(0.56-1.13)$ \\
\hline No & $521(75.4)$ & $122(23.4)$ & $399(76.6)$ & 1.00 \\
\hline \multicolumn{5}{|c|}{ Presence of children (0-4 years) in household } \\
\hline Yes & $49(7.1)$ & $10(20.4)$ & $39(79.6)$ & $0.91(0.51-1.61)$ \\
\hline No & $639(92.9)$ & $143(22.4)$ & $496(77.6)$ & 1.00 \\
\hline Presence of el & & & & \\
\hline Yes & $300(43.7)$ & $73(24.3)$ & $227(75.7)$ & $1.17(0.88-1.55)$ \\
\hline No & $386(56.3)$ & $80(20.7)$ & $306(79.3)$ & 1.00 \\
\hline Tested or char & & & & \\
\hline Yes & $399(59.9)$ & $117(29.3)$ & $282(70.7)$ & $2.17(1.54-3.05)$ \\
\hline No & $267(40.1)$ & $36(13.5)$ & $231(86.5)$ & 1.00 \\
\hline Home character & & & & \\
\hline Residence loce & & & & \\
\hline Town & $372(53.9)$ & $78(21)$ & $294(79)$ & $0.87(0.66-1.15)$ \\
\hline Others & $318(46.1)$ & $76(23.9)$ & $242(76.1)$ & 1.00 \\
\hline Fire extinguish & & & & \\
\hline Yes & $474(69.2)$ & $117(24.7)$ & $357(75.3)$ & $1.48(1.05-2.09)$ \\
\hline No & $211(30.8)$ & 35 (16.6) & $176(83.4)$ & 1.00 \\
\hline Carbon mono & & & & \\
\hline Yes & $261(37.9)$ & $73(28)$ & $188(72)$ & $1.47(1.11-1.94)$ \\
\hline No & $427(62.1)$ & $81(19)$ & $346(81)$ & 1.00 \\
\hline Previous fires & & & & \\
\hline Yes & 78 (11.3) & 15 (19.2) & $63(80.8)$ & $0.84(0.52-1.36)$ \\
\hline No & 612 (88.7) & 139 (22.7) & 473 (77.3) & 1.00 \\
\hline Supplemental & & & & \\
\hline Yes & $123(17.9)$ & $30(24.4)$ & $93(75.6)$ & $1.12(0.79-1.59)$ \\
\hline No & $566(82.1)$ & $123(21.7)$ & $443(78.3)$ & 1.00 \\
\hline Home had ba & & & & \\
\hline Yes & $594(86)$ & $120(20.2)$ & $474(79.8)$ & $0.57(0.42-0.79)$ \\
\hline No & $97(14)$ & $34(35.1)$ & $63(64.9)$ & 1.00 \\
\hline Home had mu & & & & \\
\hline Yes & $361(52.2)$ & 45 (12.5) & $316(87.5)$ & $0.38(0.27-0.51)$ \\
\hline No & $330(47.8)$ & $109(33)$ & $221(67)$ & 1.00 \\
\hline Property dam & & & & \\
\hline Yes & $103(15)$ & 11 (10.7) & $92(89.3)$ & $0.44(0.24-0.78)$ \\
\hline No & $583(85)$ & $141(24.2)$ & $442(75.8)$ & 1.00 \\
\hline Property poor & & & & \\
\hline Yes & $136(19.8)$ & $13(9.6)$ & $123(90.4)$ & $0.37(0.22-0.65)$ \\
\hline No & $550(80.2)$ & $139(25.3)$ & $411(74.7)$ & 1.00 \\
\hline Home owners & & & & \\
\hline Own & $619(89.8)$ & $143(23.1)$ & $476(76.9)$ & $1.47(0.84-2.57)$ \\
\hline Rent & 70 (10.2) & 11 (15.7) & $59(84.3)$ & 1.00 \\
\hline
\end{tabular}

were slightly more likely to be protected. The remaining variables showed a weak association with protection status.

Among home characteristics, having either a fire extinguisher or carbon monoxide detector in the home was associated with increased likelihood of being fully protected. Homes with a basement or multiple levels were less likely to be fully protected than homes without, as were homes that were either poorly cleaned or poorly maintained.
The combination of variables that best predicted NFPA protection status are listed in table 3. Factors associated with increased likelihood of being fully protected were educational status, the presence of a carbon monoxide detector, and changing smoke alarm batteries within the last six months. Factors associated with decreased likelihood of being fully protected included homes with multiple levels, homes with a basement, homes that reported previous fires, and homes 
Table 3 Multivariate binomial model of characteristics that best predict likelihood of homes being fully protected

\begin{tabular}{ll}
\hline Occupant/home characteristics & Risk ratio $(95 \% \mathrm{Cl})$ \\
\hline $\begin{array}{l}\text { At least one resident had a high school or higher } \\
\text { education }\end{array}$ & $3.96(1.04-15.08)$ \\
Yes & 1.00 \\
No & \\
Tested or changed smoke alarm battery in past \\
6 months \\
Yes \\
No & $1.77(1.26-2.48)$ \\
Previous fires on property & 1.00 \\
Yes & $0.72(0.49-1.06)$ \\
No & 1.00 \\
Carbon monoxide detector at home & $1.24(0.96-1.60)$ \\
Yes & 1.00 \\
No & $0.43(0.31-0.60)$ \\
Home had multiple levels & 1.00 \\
Yes & \\
No & $0.52(0.29-0.91)$ \\
Property poorly cleaned or cluttered & 1.00 \\
Yes & \\
No & $0.76(0.57-1.02)$ \\
Home had basement & 1.00 \\
Yes & \\
No & \\
\hline
\end{tabular}

that were poorly cleaned or cluttered. This model had a deviance of 0.96 .

A Monte Carlo simulation using a random 66\% sample indicated consistency in the multivariate model estimates over 10 rounds of sampling. The only variable to drop out of the model was education, which was not included in three of the 10 models. This is consistent with the instability of the estimate for education, which is largely driven by the high proportion of households that had at least one high school graduate. The deviance estimates for these 10 rounds ranged from 0.88 to 0.99 .

\section{DISCUSSION}

Only $22.3 \%$ of homes, or approximately one in five, were adequately protected according to NFPA guidelines. More than half of the homes with smoke alarms did not have enough of them or had installed them incorrectly, and $42.4 \%$ of homes with alarms had at least one alarm that did not operate. Most homes (86\%) had purchased and installed at least one smoke alarm, and $71.6 \%$ of homes had at least one functional smoke alarm. These findings indicate that the majority of residents who have put smoke alarms in their home have not installed them to gain maximum protection. Studies that report only smoke alarm function, and not placement, may overestimate the level of fire protection among households.

Many individual and household characteristics that previous literature has shown to be associated with the presence of smoke alarms in the home were weakly associated with whether or not the home was fully protected. Research to date suggests that older homes, ${ }^{10} 2930$ residents with low income, ${ }^{10} 1213163132$ low educational levels, ${ }^{10}{ }^{12}$ and homes with smokers ${ }^{12}{ }^{14}{ }^{33}$ are less likely than are other homes to be protected by a working smoke alarm. Some studies have found that homes with a young child were more likely to have a smoke alarm, ${ }^{16}{ }^{17}$ and homes with elderly residents were less likely to have a smoke alarm. ${ }^{13}{ }^{30}$ Other studies have found no association by age of resident. ${ }^{12}$

Among these variables previously studied in relation to smoke alarm presence, only educational status was a strong predictor of full protection. The relation between educational status and full protection may indicate that information about the proper number and placement of alarms is not easily accessible to the general population and may be difficult to understand for individuals with poor literacy skills.

Home characteristics including multiple levels, the presence of a basement, and being poorly cleaned or cluttered were independently associated with a reduced likelihood of being fully protected. These home factors have not been associated with smoke alarm ownership in existing literature. Larger homes, especially those with basements, require additional alarms for full protection. Our findings indicate that residents are not aware of the appropriate number of alarms needed to protect their households.

Basements may present unique fire hazards because they are a frequent location for storage of potentially flammable hazardous substances, such as paints and cleaners. They are also commonly used for non-permitted sleeping quarters which may not have appropriate egress. The lack of smoke alarm coverage in basements is an especially important consideration in the Midwest, where homes commonly have basements. Cluttered homes may also pose an increased risk for fire. Because of a potential fire risk, full smoke alarm protection is a high priority for these homes.

This study has several important strengths. Measurement of smoke alarm placement and function was done through in-home inspection. Most previous studies have relied on self reported phone interviews, and respondents may overreport function. Assessment of smoke alarm installation by NFPA guidelines would be difficult using phone interviews. Smoke alarm function was measured with a chemical smoke challenge, and the reported proportion of homes with functional smoke alarms may thus be lower than studies that rely on self report. ${ }^{11}$

This study also has limitations. The low participation rate reduces the extent to which study households represent the general population. Study households agreed to participate in a longitudinal follow up, and homes willing to participate in such a study may be more likely to have smoke alarms. Thus, study homes may overrepresent the actual number of homes that are fully protected in the general population. Study homes were located in a rural county and are not likely to represent urban populations. Time dependent variables collected from the original cohort study, such as alcohol use and depression, could have changed between participation in the cohort study and the baseline assessment for the smoke alarm study.

Our findings indicate that consumers may not be knowledgeable about the number of alarms they need, where they need to be placed, and how to install them. Information about installing smoke alarms is available on a number of websites, such as those maintained by the US Fire Administration (http://www.usfa.fema.gov/safety/alarms/), the Home Safety Council (http://www.homesafetycouncil. $\mathrm{org} / \mathrm{safety}$ guide/sg_fire_w005.aspx), the Fire Safety Council (http://www.firesafetycouncil.com/english/pubsafet/ fasa.htm) and some manufacturers. However, consumers who do not use a computer or who have low literacy may have difficulty accessing or understanding this information. Others may not know that these resources exist.

Agencies that promote fire safety should increase their focus on installation guidelines. These agencies include local and state health departments, fire departments, schools, doctor's offices, hospitals, burn units, community centers, and safety coalitions. One focus should be on the development of materials appropriate for specific communities based on literacy levels and language preferences. A second focus should be dissemination of this information through appropriate mechanisms, such as public media campaigns, community centers, school based educational programs, or within electric bills. 


\section{Key points}

- Although $86 \%$ of the 691 participating homes had a working smoke alarm, only one in five homes were adequately protected according to National Fire Protection Association guidelines.

- Homes with at least one high school or higher education were nearly four times more likely to be fully protected, which indicates that information about smoke alarm installation and placement may be difficult to obtain or understand for households with low literacy.

- Homes with multiple levels or with basements were much less likely to be fully protected. Owners may not be aware of the number of alarms needed in their homes, and often fail to consider the fire hazards frequently found in basements.

- Programs that promote fire safety or smoke alarm use may be ideal venues to provide easy to understand information about installation guidelines.

Programs that provide smoke alarms at low or no cost should also focus on the installation of alarms. Although there have been many successful efforts to provide free or low cost smoke alarms throughout the country, not all programs assist with the installation of these alarms. ${ }^{12} 3134$ When possible, smoke alarm give-away programs should try to assess the number of alarms needed in each participant's home based on the number of levels, including the basement, and the number of sleeping areas. With these efforts, the two important goals of increasing the number of homes with working smoke alarms and increasing the number of homes that are fully protected can be completed together.

\section{ACKNOWLEDGEMENTS}

We would like to acknowledge Dr James Merchant, Ann Stromquist, Jill Moore, Jamie Johnson, and Janelle Edmondson from the Rural Health Study, Genna Herron and Paul Whitten from the University of Iowa Injury Prevention Research Center, and Arthur Lee from the Consumer Product Safety Commission. This work was supported by the University of Iowa Injury Prevention Research Center (CDC/ NCIPC CCR 703640) and the Great Plains Center for Agricultural Health (CDC/NIOSH U07/CCU706145), both housed in the University of Iowa, College of Public Health, Department of Occupational and Environmental Health.

\section{Authors' affiliations}

C Peek-Asa, V Allareddy, J Yang, J Lundell, C Zwerling, University of lowa Injury Prevention Research Center, lowa City, IA, USA

C Peek-Asa, C Taylor, C Zwerling, University of lowa, College of Public Health, Department of Occupational and Environmental Health, lowa City, IA, USA

V Allareddy, University of lowa, College of Public Health, Department of Health Management and Policy, lowa City, IA, USA

J Yang, University of lowa, College of Public Health, Department of Community and Behavioral Health, lowa City, IA, USA

C Taylor, University of lowa Center for Agricultural Safety and Health, lowa City lowa, USA

This study was approved by the University of lowa Human Subject Protection Committee.

\section{REFERENCES}

1 Karter JM. Fire loss in the United States during 2002. Quincy, MA: National Fire Protection Association, 2003

2 The rural fire problem in the United States. Washington, DC: Federal Emergency Management Agency, United States Fire Administration, 1997.

3 Accident facts, 1998 edition. Itasca, IL: National Safety Council, 1998.

4 Shults R, Harvey P. Efforts to increase smoke detector use in U.S. households: an inventory of programs. Atlanta, GA: CDC, National Center for Injury Prevention and Control, 1996.

5 Runyan CW, Bangdiwala SI, Linzer MA, et al. Risk factors for fatal residential fires. N Engl J Med 1992;327:859-63.

6 Hall JR Jr. The U.S. experience with smoke detectors: Who has them, How well do they work? When don't they work? NFPA J 1994:36-46.

7 Smith CL. Smoke detector operability survey - report on findings (revised). Bethesda, MD: U.S. Consumer Product Safety Commission, 1994.

8 Ahrens M. U.S. experience with smoke alarms and other fire alarms: Who has them? How well do they work? When don't they work? Quincy, MA: National Fire Protection Association, 1998.

9 Douglas MR, Mallonee S, Istre GR. Estimating the proportion of homes with functioning smoke alarms: a comparison of telephone survey and household survey results. Am J Public Health 1999;89:1112-14.

10 Harvey PA, Sacks JJ, Ryan GW, et al. Residential smoke alarms and fire escape plans. Public Health Rep 1998;113:459-64.

11 McGwin G, Chapman V, Rouseculp M, et al. The epidemiology of fire-related deaths in Alabama, 1992-1997. J Burn Care Rehabil 2000;21:75-83.

12 Shults RA, Sacks JJ, Briske LA, et al. Evaluation of three smoke detector promotion programs. Am J Prev Med 1998;15:165-71.

13 McKnight RH, Struttmann TW, Mays JR. Finding homes without smoke detectors: one step in planning burn prevention programs. J Burn Care Rehabil 1995; 16:548-56.

14 Rowland D, DiGuiseppi C, Roberts I, et al. A prevalence of working smoke alarms in a local authority inner city housing: randomized controlled trial. BMJ 2002;325:998-1001.

15 DiGuiseppi G, Roberts I, Speirs N. Smoke alarm installation and function in inner London council housing. Arch Dis Child 1998;81:400-3

16 Forjuoh SN, Coben JH, Dearwater SR, et al. Identifying homes with inadequate smoke detector protection from residential fires in Pennsylvania. J Burn Care Rehabil 1997; 18:86-91.

17 Roberts I. Smoke alarm use: prevalence and household predictors. Inj Prev 1996;2:263-265.

18 Shaw KN, McCormick MC, Kustra SL, et al. Correlates of reported smoke detector usage in an inner-city population: participants in a smoke detector give-away program. Am J Public Health 1988;78:650-3.

19 Runyan CW, Johnson RM, Yang J, et al. Risk and protective factors for fires, burns, and carbon monoxide poisoning in US Households. Am J Prev Med 2005;28:102-8.

20 National Fire Alarm Code, NFPA 72. Quincy, MA: National Fire Protection Association, 1999.

21 Merchant JA, Stromquist AM, Kelly KM, et al. Chronic disease and injury in an agricultural county. J Rural Health 2002;18:521-35.

22 Buchsbaum DG, Buchanan RG, Centor RM, et al. Screening for alcohol abuse using CAGE scores and likelihood ratios. Ann Intern Med 1991;155:774-7.

23 Ewing JA. Detecting alcoholism: the CAGE questionnaire. JAMA 1984;252:1905-7.

24 Mayfield DG, McLeod G, Hall P. The CAGE questionnaire: validation of a new alcoholism screening instrument. Am J Psychiatry 1974;131:1121-3.

25 Kohout FJ, Berkman LF, Evans DA, et al. Two shorter forms of the CES-D Depression Symptoms Index. J Aging Health 1993;5:179-93.

26 Radloff LS. The CES-D scale: a self-report depression scale for research in the general population. Appl Psychol Measurement 1977;1:385-401.

27 Skov T, Deddens J, Petersen MR, et al. Prevalence proportion ratios: estimation and hypothesis testing. Int J Epidemiol 1998;27:91-5.

28 Hosmer DW, Lemeshow S. Applied logistic regression. New York: John Wiley \& Sons, Inc, 1989.

29 McLoughlin E, Marchone M, Hanger SL, et al. Smoke detector legislation: its effect on owner-occupied homes. Am J Public Health 1985;75:858-62.

30 Centers for Disease Control (CDC). Prevalence of smoke detectors in private residences-DeKalb County, Georgia, 1985. MMWR Morb Mortal Wkly Rep 1986;35:445-8.

31 Mallonee $S$, Istre GR, Rosenberg $M$, et al. Surveillance and prevention of residential-fire injuries. N Engl J Med 1996;335:27-31.

32 Jones AR, Thompson CJ, Davis MD. Smoke alarm ownership and installation: a comparison of a rural and a suburban community in Georgia. J Community Health $2001 ; 26: 307-28$

33 Ballard JE, Koepsell TD, Rivara F. Association of smoking and alcohol drinking with residential fire injuries. Am J Epidemiol 1992;135:26-34.

34 DiGuiseppi C, Higgins JP. Interventions for promoting smoke alarm ownership and function. Cochrane Database of Systematic Reviews $2001 ;(2): C D 002246$. 